Maria Lúcia Magalhães Bosi ${ }^{1}$

${ }^{1}$ Laboratório de Avaliação e Pesquisa Qualitativa em Saúde (LAPQS), Departamento de Saúde Comunitária, Faculdade de Medicina, Universidade Federal do Ceará. Rua Prof. Costa Mendes 1608/5², Rodolfo Teófilo. 60430-140 Fortaleza CE. malubosi@ufc.br

\section{Pesquisa qualitativa em saúde coletiva: panorama e desafios}

\section{Qualitative research in collective health: overview and challenges}




\section{Introdução}

Este artigo desdobra e aprofunda reflexões que desenvolvemos em outras publicações, compondo uma trajetória voltada ao adensamento do enfoque qualitativo na pesquisa em Saúde (Coletiva). Mais que um esforço de revisão da literatura nesse domínio ou uma visita à empiria, ainda que também se incluam no exercício aqui realizado, trata-se de um balanço alicerçado no acumulo oriundo da minha práxis acadêmica nessa tradição de Pesquisa.

Com base no panorama que gradualmente veio se descortinando ao longo desse percurso e ciente dos riscos impostos pelo limite de espaço, visitarei aqui alguns objetos nucleares no debate atual no campo, bem como outros ainda não suficientemente contemplados, compartilhando algumas reflexões acerca de certos desafios que se apresentam para o enfoque qualitativo, referidos ao contexto cientifico brasileiro e, mais especificamente, ao campo da saúde coletiva.

No que concerne ao que denomino como Pesquisa Qualitativa (PQ), reitero a acepção já tratada em publicações anteriores ${ }^{1,2}$ nas quais demarcamos qualidade/qualitativo(a) na interface com a subjetividade. Tal delimitação resulta em que a referida adjetivação, quando aplicada à pesquisa, caracteriza aquelas cujos objetos exigem respostas não traduzíveis em números, haja vista tomar como material a linguagem em suas várias formas de expressão. Por ora, me deterei nesta aproximação preliminar aos contornos da Pesquisa Qualitativa, mas retornarei adiante ao plano conceitual, pelo fato de alguns desafios que pretendo examinar dizerem respeito precisamente a este âmbito.

Quanto à Saúde Coletiva (SC), é preciso reconhecê-la, sobretudo, como um campo, conceito que encontra uma definição estratégica na teoria dos campos sociais transversal à obra de Pierre Bourdieu ${ }^{3}$, na qual campo científico corresponde a um espaço de luta concorrencial no qual o que está em jogo são os monopólios da autoridade científica [...] e da competência científica [...] socialmente outorgadas.

Ao lançar mão deste conceito, pretendo marcar distância da noção de "área de conhecimento" tal como a SC figura nas taxonomias das agências de fomento brasileiras. Isso porque longe de prevalecer no campo cientifico uma lógica imanente de divisão disciplinar ou de desenvolvimento científico por superação de paradigmas ${ }^{4}$, conforme o termo área pode sugerir, tal movimento é analisado de forma bastante lúcida por Bour- dieu $^{3}$ quando afirma serem reciprocamente os conflitos epistemológicos inseparavelmente conflitos políticos. "Campo" é, portanto, um conceito que devolve ao espaço científico sua dimensão politica, revelando-se, assim, fortemente estratégico para entendermos sua "economia interna" e as disputas que se expressam em debates conceituais ou metodológicos, mas com reflexos decisivos nos planos político e econômico. Não obstante alianças epistêmicas, a presença de tensões paradigmáticas $^{5}$ nesse espaço representa um fenômeno de particular interesse para análises voltadas aos desafios do enfoque qualitativo nesse campo.

Quanto às tentativas de definir SC, uma consulta aos esforços realizados por vários autores nos leva a constatar um consenso quanto a demarcá-la, a um só tempo, como campo de conhecimento e âmbito de práticas ${ }^{6,7}$, portanto, como campo e movimento. Sua constituição interna se fundamenta em três núcleos de saberes ${ }^{5}$ ou espaços e formações disciplinares ${ }^{8}$, que correspondem à Epidemiologia, à parcela das Ciências Humanas e Sociais (CHS) incorporadas ao campo e a um terceiro núcleo que, sob várias denominações, se ocupa das Politicas, da Planificação e da Gestão de Sistemas de Saúde.

Cabe assinalar que a Epidemiologia persiste como o núcleo hegemônico nesse campo, aspecto que, conforme examinado adiante, subjaz a vários desafios com que se depara o enfoque qualitativo.

Feitas essas demarcações, e antes de passar ao subtítulo focalizando o objeto em destaque na presente discussão, visitemos rapidamente o cenário atual da Pesquisa Qualitativa em Saúde Coletiva (PQSC) como ponto de partida para a problematização aqui pretendida.

\section{Acerca do estatuto atual da pesquisa qualitativa na saúde coletiva}

A abordagem qualitativa apresenta-se como uma orientação cada vez mais difundida no âmbito da saúde (coletiva) nesta virada de século?. Tal ascensão, embora não deva ser apressadamente interpretada como legitimidade inequívoca ante outros paradigmas e, menos ainda, como hegemonia ${ }^{10}$ desse enfoque sobre os demais na SC, certamente vem merecendo atenção no campo. Dentre outros aspectos, e aceitando-se como premissa que as questões de pesquisa vinculamse aos problemas da existência humana, esse incremento pode ser compreendido também como resposta a certos desafios, em todos os campos do saber e esferas da vida; problemas esses que transcendem as potencialidades do modelo tra- 
dicional, no caso da saúde, o modelo da ciência positiva.

No âmbito da pesquisa, isso significa investimentos em estudos de processos humanos em lugar de tão somente estocar biotecnologias - que, a despeito de sua indiscutível importância, apenas serão úteis se e quando assimiladas culturalmente.

Contudo, apesar do crescimento e reconhecimento alcançados, o enfoque qualitativo ainda se depara com um conjunto de desafios para a afirmação plena do seu estatuto nos vários domínios do campo cientifico, não sendo a SC, a despeito do seu discurso oficial, exceção. Não obstante sua pretensa interdisciplinaridade e sua emergência se alinhar a um movimento orientado por um ideário que convoca a subjetividade ao aludir a princípios como qualidade; equidade; integralidade; participação, dentre outros vinculados à reforma sanitária brasileira $(\mathrm{RSB})^{6,7}$ e que norteiam o Sistema Único de Saúde (SUS) pretendido, a pesquisa qualitativa vem se deparando com sérios obstáculos no interior desse campo, conforme procuraremos evidenciar.

Muitos elementos já vêm sendo interrogados por diversos autores no debate sobre o referencial das CHS na Saúde coletiva. Contudo, o campo ainda demanda análises que possam subsidiar reflexões e ações, em especial no que tange especificamente à pesquisa qualitativa. A presente discussão se origina, antes de tudo, no desconforto ante o que acabamos de assinalar e no desejo de contribuir para o aprofundamento desse debate, fortalecendo o projeto original da SC como campo e movimento.

\section{Desafios contemporâneos}

No intuito de examinar essas afirmações, sobretudo a contradição apontada no último parágrafo, transitarei agora para os desafios que se apresentam no panorama atual do enfoque qualitativo na SC. Cabe ressalvar que, na impossibilidade de esgotá-los nesta breve análise, focalizarei aqueles cujos desfechos considero mais decisivos para a consolidação do referido enfoque nesse espaço especifico.

Como estratégia de exposição, sistematizarei a discussão em tópicos sequenciais, reconhecendo de antemão a presença de várias conexões entre os mesmos ainda que os temas tratados se situem em níveis distintos. Assim, na discussão que se segue, observa-se um trânsito progressivo do plano dos conceitos ao nível das práticas em SC. Partindo de questões situadas no que aqui denomino plano epistêmico ou teórico-concei- tual, focalizarei, gradualmente: aspectos éticos e operacionais da PQ; o lugar reservado a esse enfoque no campo científico; o plano da formação, culminando em desafios relacionados à transferência de conhecimento com vistas à consolidação das reformas já em curso ou pretendidas para o setor.

\section{Pesquisa qualitativa: do que estamos falando?}

Ao inaugurar esta explanação com uma definição genérica de pesquisa qualitativa, fiz a ressalva de que seria preciso retornar a este tema e reexaminá-lo. Inicio comentando algumas posturas, ainda muito generalizadas, que se polarizam no que qualifico, por um lado, como confusão e, no outro polo, como reducionismo. Exemplificarei com apenas três problemas que ilustram tais posturas e remetem ao: emprego dos conceitos, uso indiscriminado de termos e, por fim, ao debate (por vezes, embate) entre os enfoques qualitativo e quantitativo. Sumarizo a seguir aspectos centrais a cada um deles.

Quanto ao emprego dos conceitos, iniciarei aludindo, uma vez mais, ao verbete qualidade, estendendo-se ao que se concebe como qualitativo. Não me alongarei neste tema, haja vista, em artigo publicado há uma década ${ }^{1}$, já termos nos detido nesses conceitos, no intuito de apontar alguns subsídios voltados à sua demarcação, discussão desdobrada posteriormente em outras publicações ${ }^{1,2}$. Entretanto, decorridos alguns anos, prossigo constatando problemas no emprego dos referidos conceitos, aspecto que longe de significar preciosismo acadêmico, vem gerando impactos em distintas esferas envolvidas na dinâmica do campo SC. Assim, vejo-me forçada a insistir nessa delimitação, situando-a como um primeiro desafio - e de grande importância, referido ao plano conceitual, mas indissociável de outros planos, conforme se verá adiante.

Sumarizando, gostaria de reiterar que na gênese dos equívocos relativos ao emprego de qualidade/qualitativo, pesa o fato de figurarem na literatura inúmeras definições de qualidade, traduzindo a multidimensionalidade dessa categoria que acaba por se expressar como polissemia. Mais que isso, importa assinalar a presença do que denominamos tensão semântica, multidimensionalidade intrínseca e multidimensionalidade extrínseca inerentes ao conceito ${ }^{1}$.

Passando ao segundo problema assinalado, atinente ao uso indiscriminado de termos, noções e conceitos, observam-se problemas quan- 
to ao emprego intercambiável de método, técni$c a$, análise, dentre outros, expressando falta de clareza no que tange ao nível a que cada um faz referência ${ }^{11,12}$. À parte o fato de ser a codificação e o uso rigoroso de terminologias e conceitos critério indiscutível de qualidade em pesquisa, qualquer que seja o enfoque ou tradição, no âmbito da PQSC tal negligencia vem gerando consequências bastante nefastas. Exemplo disso é o fato de a natureza do estudo ser, muitas vezes, definida pela técnica empregada, sem o necessário fundamento epistemológico. Contudo, os estudos qualitativos não se caracterizam apenas por utilizarem certas técnicas, nem tampouco por aludirem a determinados termos ou conceitos: [...]. A frequente redução de um plano a outro possibilita [...] que o (mero) emprego substitua a necessária 'postura qualitativa', ou seja, um fundamento epistemológico, no qual as técnicas façam sentidoum método - e do qual as mesmas se originem ${ }^{13}$.

Finalizando com o terceiro aspecto destacado neste primeiro desafio, cabe comentar as disputas qualitativo-quantitativo, já amplamente analisadas na literatura ${ }^{14-17}$. Na práxis da pesquisa e nos debates sobre o tema na SC, observa-se que tais paradigmas ora são considerados enfoques alternativos para uma mesma questão, ora paradigmas em disputa pelo status de approach superior. Uma terceira posição, na polaridade oposta, assume uma harmonia paradigmática olvidando as descontinuidades e as rupturas entre os mesmos. Defendo que, em cada uma dessas leituras ou polarizações, ocultam-se graves lacunas de compreensão no que concerne à multidimensionalidade do fenômeno saúde, gerando obstáculos para a necessária interdisciplinaridade no campo.

Examinando-se a primeira posição, na qual os enfoques são tomados como alternativos posição, não raro, expressa na interrogação sobre qual enfoque adotar para um dado objeto, a resposta a nosso ver pode ser dada evocando tão somente o nível ontológico: a natureza do objeto condena ao método. Portanto, não há alternati$v a$ : se a aferição do nível glicêmico não pode ser realizada mediante o emprego de grupos focais e ninguém ousaria fazê-lo reivindicando legitimidade cientifica, como a compreensão de processos subjetivos poderá ser empreendida cientificamente mediante instrumentos voltados a mensurar afetos e simbolizações submetendo este material a testes estatísticos (!)?

Quanto às posturas assinaladas no interior de disputas qualitativo-quantitativo, de um ponto de vista epistemológico, uma vez que se trata de modelos distintos, não tem sentido arguir um paradigma com base em parâmetros que não lhe dizem respeito e não o constituem. Assim, o que acabo de afirmar no que concerne à adequação método-objeto parece servir também como resposta às disputas relativas à superioridade dos enfoques, qualitativo ou quantitativo. O encaminhamento atual do debate aponta como via mais promissora a complementaridade ${ }^{16,18,19}$.

Por fim, no que concerne à pretensa harmonia paradigmática, embora menos presentes na literatura e mais nos fóruns e eventos, da mesma forma, circulam posições igualmente equivocadas. Estas, supostamente dialéticas, destituem até mesmo a pertinência da adjetivação pesquisa qualitativa, considerada redutora sob o argumento de que a realidade admite aproximações qualitativas e quantitativas. Ora, tal postura, além de confundir a natureza do 'real' com a dos enfoques voltados a apreendê-lo, objetos bastante distintos, na polaridade oposta do que supõe defender, reforça um discurso de indiferenciação epistemológica, como se tudo fosse o mesmo, e pesquisa qualitativa uma invenção improcedente e até mesmo leviana.

Na prática, isso resulta em prejuízos à legitimação e ao ganho em capital simbólico e social ${ }^{3}$ do referido enfoque no campo cientifico e, em particular, na SC. Conforme veremos mais à frente, quem protagoniza o enfoque qualitativo não são os mesmos atores que alavancam o modelo biomédico ou epidemiológico-descritivo; tampouco os recursos que apoiam o primeiro são do mesmo vulto e derivam dos mesmos fundos que incentivam este último. Portanto, apagar as diferenças é uma postura, além de equivocada no nível ontológico, perigosa no que concerne à práxis no campo.

\section{Taxonomias, nomenclaturas, vertentes}

$\mathrm{Na}$ continuidade do que acabo de examinar, tratarei de forma mais especifica outro desafio conceitual, referente à questão das taxonomias e terminologias utilizadas pelos pesquisadores qualitativos. Ao adentrar nessa discussão, vejo-me transportada ao mito bíblico da Torre de Babel, narrativa bastante conhecida do Antigo Testamento $^{20}$. Dentre os significados desse intrigante mito bíblico, um deles me chama poderosamente a atenção: a alusão à diversidade de idiomas que separa a humanidade e que soa como metáfora do que pretendo comentar neste tópico.

Qualquer um de nós ao ingressar na PQ - e mesmo aqueles que frequentam esse âmbito há algum tempo, provavelmente se sentirá como os 
discípulos de Noé que ao subirem a torre de Babel, se viram em meio a uma confusão de idiomas. É fato que a $\mathrm{PQ}$, mais ainda na SC, é marcada pela interdisciplinaridade, nutrida por vários referenciais e por conceitos complexos e interconectados, oriundos de teorias densas, de vários alcances. Contudo, cabe reconhecer serem necessários investimentos e uma cuidadosa reflexão sobre o assunto. Não obstante, reflexões e sobretudo proposições acerca da terminologia nesse enfoque são ainda escassas na literatura, ainda que se localizem alguns registros ${ }^{12}$. Dentre as várias indagações a serem feitas destaco algumas que me parecem pertinentes: em que medida essa pluralidade de idiomas se deve efetivamente à diversidade epistemológica e disciplinar que permeia a área? Quais os efeitos na interdisciplinaridade pretendida por essa tradição?

Tal como afirmei há pouco em relação à impossibilidade de definição unívoca do termo pesquisa qualitativa, também aqui cabe reconhecer que a diversidade disciplinar constitutiva desse enfoque impede advogar por uma codificação homogênea que neutralizaria sua origem interdisciplinar. Contudo, são preocupantes certas tendências que, no limite, levariam a admitir tantos modelos quantos investigadores existentes, resultando na multiplicação ad infinitum de vertentes e nomenclaturas particulares, como se estivéssemos sempre partindo do zero ou fundando escolas. Será mesmo justificável tal procedimento ou deveríamos investir na busca de outras alternativas que viessem a facilitar o diálogo não apenas inter, mas intraenfoques na SC?

No que concerne às taxonomias (e paradigmas) em pesquisa qualitativa, a exemplo daqueles propostos por autores como Denzin e Linco$\ln ^{14}$, Cresweel ${ }^{15,21}$, Morse e Field ${ }^{22}$ a questão não consiste apenas na dificuldade de 'enquadre' nesses tipos-ideais, mas, na própria separação, por vezes, demasiado estanque, entre as modalidades. Esse aspecto nos motivou a sugerir, em outro texto, caracterizações (em lugar de paradigmas) de tipo fuzzy, ou seja, mais transicionais ${ }^{13}$. Isso porque, na nossa experiência, grosso modo, as pesquisas se enquadram no entre dessas tipologias, ainda que nem sempre isso se mostre bem assimilado. Talvez lugares transicionais viessem a diminuir a angustia, ou crise de identidade, de quem tenta se situar no interior desse enfoque, em especial, na SC.

Não bastassem os problemas relativos aos paradigmas, é em relação à identificação das vertentes no interior das distintas orientações ou paradigmas que a imagem do mito de Babel pa- rece incidir ainda com mais força. Para evidenciar a dificuldade a que estou me referindo, mencionarei o elenco citado por Tesch ${ }^{11}$ em seu conhecido livro Qualitative Research: Analysis Types \& Softwares Tools. Importa argumentar que a despeito da diversidade e da explosão de experiências referidas por Denzin e Lincoln ${ }^{14}$ como traço das etapas mais recentes do desenvolvimento da Pesquisa Qualitativa, consideramos um desafio esta multiplicidade de rótulos designando paradigmas, teorias, métodos, enfoques e/ ou estratégias de pesquisa.

Essa situação, ao que parece, não se revela exclusiva do nosso contexto, conforme ilustra a carta de uma aluna de Michael Patton publicada no seu livro Qualitative Research \& Evaluation Methods ${ }^{23}$ demonstrando quão difícil é, por vezes, se inserir em um paradigma e/ou vertente. Em sua carta, a aluna se revela perdida e finaliza suplicando ao Dr Patton: - Wich approach is right? [...] Help!!!.

Quanto à lista publicada no texto de $\operatorname{Tesch}^{11} \mathrm{a}$ autora adverte: The problem with this list is not that is far too long, but that some of the terms overlap with or are synonyms for others, and not all terms are on the same conceptual level. Certos termos se referem ao plano epistemológico enquanto outros designam métodos de análise ou mesmo técnicas especificas.

Partindo dessa assertiva que sintetiza o âmago da questão, cabe indagar: como no interior da tradição qualitativa vem se legitimando novas vertentes e se consagrando nomenclaturas? Confundir rótulos com vertentes fragiliza a totalidade do enfoque e seu potencial - consistindo no que denominarei, à falta de uma melhor expressão, pseudoescolas.

Se seguirmos nessa direção, aprofundaremos uma confusão de idiomas que impede o diálogo como no mito bíblico. Não seria o caso de, no interior desse enfoque, investirmos em estratégias que auxiliem a identificar idiomas comuns, ainda que respeitando sotaques, entonações e certas singularidades, em lugar de seguirmos criando idiomas inteligíveis apenas em círculos por vezes bastante restritos?

\section{Incorporação de novas contribuições e as 'alianças' entre saberes}

Com efeito, o caráter complexo $0^{24}$ dos objetos de que se ocupam as pesquisas qualitativas desafia as vertentes atuais e convida a novas orientações e à formulação de novas técnicas de investigação. Quanto a isso, e concordando com o que 
predomina na literatura ${ }^{14,23}$, há que se preservar a flexibilidade permitindo a necessária adaptação e recriação de modelos.

Tal posicionamento, fique claro, não conflita com o que acabei de defender no que concerne às terminologias e taxonomias, já que a tarefa não se reduz a (re)criar novos rótulos mas vertentes inovadoras, ou seja, novas construções, devidamente fundamentadas. A flexibilidade defendida implica o entendimento profundo de que enfoques se vinculam a tradições epistemológicas, teorias e conceitos que precisam ser identificados, de modo a que a opção possa ser adequadamente justificada e operacionalizada.

Feita a ressalva, o momento demanda, mais do que nunca, inovação, convidando não apenas à interdisciplinaridade, mas à inter(trans)culturalidade. Ao me referir à interculturalidade $\mathrm{e}^{25} \mathrm{e}$ não somente à interdisciplinaridade, pretendo operar um deslocamento nesta discussão do âmbito científico estrito ampliando-a para outras arenas sociais. Nestas são produzidos, se não conhecimentos disciplinados pela racionalidade científica moderna, saberes 'nativos' que precisam formar alianças, religarem-se $e^{26}$ a outros, processo de importância primordial para o campo da Saúde Coletiva.

O desafio inclui, assim, a incorporação de outras contribuições e saberes, notadamente as artes - cinema, teatro, fotografia, pintura, literatura, conforme já vem se dando em muitos espaços, ainda que o tema seja polêmico e se localizem resistências ${ }^{27}$. Certamente, há que combinar aprendizado científico com o desenvolvimento de outras dimensões - artística, intuitiva, dialógica. Mas, cuidando das 'aventuras'. Portanto, o que postulo é ousadia com rigor.

Ao defender o rigor, a despeito das criticas que poderei sofrer em um momento que clama por desconstruções, faço-o assumindo uma clara posição: o projeto e o movimento da pesquisa qualitativa, aqui referidos ao âmbito da saúde coletiva, não podem prescindir de uma reflexão acerca da qualidade do que vem sendo produzido. Quanto a isso, a literatura especializada é prolífera no que tange a dimensões e respectivas estratégias de avaliação da qualidade de pesquisas qualitativas, tendendo ao reconhecimento consensual de que a conquista desses padrões é, tal como aqui demarcamos, um importante desafio ${ }^{19}$. Sobretudo, quando o enfoque vem ganhando cada vez mais espaço nos periódicos científicos na SC. Mas o que significa pesquisa qualitativa de 'qualidade'?

Sem desmerecer (e tampouco excluir) os parâmetros técnicos a serem alcançados, mas le- vando em conta as considerações feitas quando da discussão do que aqui consideramos postura qualitativa, sustento que a pesquisa qualitativa de qualidade será aquela que apresentar coerência e consistência simultaneamente em três níveis: ontológico, metodológico e ético.

Tal tríade significa, antes de tudo, delimitar claramente um objeto cuja natureza se coadune com o enfoque, empregando conceitos adequados às vertentes eleitas, reconhecendo vínculos ante as distintas tradições, adotando modelos abertos de pesquisa e procedimentos indutivos, mantendo a reflexividade como principio orientador $^{28}$. Reflexividade, entendida como consciência autocrítica em todo o processo da pesqui$\mathrm{sa}^{29,30}$ garantindo a integração e a operacionalização dialéticas das distintas etapas, assumindo transcrição, tradução ou 'coleta de dados', como problemas teóricos ${ }^{31,32}$.

Se problemas relacionados às técnicas demandam teorização - são, portanto, problemas teóricos, há também que considerar problemas éticos como problemas teóricos, ou seja, inserir preocupações éticas como item de rigor ${ }^{33}$ na produção negociada de evidências - expressão que emprego em lugar de "coleta de dados", por entender esta última, não obstante sua ampla utilização por parte de pesquisadores qualitativos, se revestir de acepções inadequadas às premissas do enfoque. Na perspectiva de PQ aqui adotada, não há nada a coletar e tampouco dados cujos significados, no nosso idioma, em sua maior parte, se aproximam de algo supostamente objetivo, que se revela de forma direta ou por antecipação. Contudo, o que se processa nas pesquisas qualitativas pertence ao plano das construções intersubjetivas, imersas em relações sociais, e não a mera aplicação de técnicas. Aceitando-se tal concepção impõe-se considerar a dimensão ético-política nas decisões em pesquisa, entendendo-as como critério de qualidade sob a ótica aqui defendida.

Finalmente, e assumindo o entendimento de que a comunicação dos resultados é parte primordial da pesquisa e possui claras interfaces com a qualidade da produção, há que cuidar das várias questões relativas à publicação de resultados que remetem ao já assinalado acerca da tradução dos "achados” e do rigor metodológico. Introduz ainda no debate a consideração dos veículos (periódicos, livros e outros) e respectivas politicas editoriais, bem como a hierarquia adotada na economia interna do campo SC: como sob o regime de produtividade atual se situam os veículos que disseminam pesquisas qualitativas? 
Como se caracteriza a velocidade de produção nessa tradição? Que constrangimentos se impõem ao enfoque qualitativo tendo em vista os ritmos de produção, a divisão do trabalho e as características das autorias?

Tais questões, dentre outras, nos levam, neste ponto do debate, a focalizar o processo de construção da ciência e as circunstâncias que cercam a PQ no chão de fábrica do campo cientifico, mais precisamente na SC, cenário da análise em curso.

Produtividade e seus impactos no âmbito da pesquisa qualitativa em saúde coletiva

Sabemos que o padrão ouro a que estamos submetidos no que concerne ao perfil a ser atingido pelos agentes produtores do conhecimento, no Brasil e em vários outros países, se funda no maior número de publicações científicas indexadas em periódicos internacionais, não importando se socialmente descontextualizadas. Nesse modelo, a ênfase recai no veículo e não no conteúdo, sendo a lógica no âmbito da produção intelectual semelhante à que prevalece na produção seriada industrial. Importa a produtividade, entendida como intensificação do ritmo que, tanto na ciência como no meio fabril e midiático, bem pode incrementar o volume do que é produzido, mas, sobretudo para a primeira, não tão certos são os ganhos no que concerne à qualidade.

Em Compreender, posfácio da obra "A Miséria do Mundo", Bourdieu ${ }^{34}$, embora se reportando à produção dos jornalistas, nos relembra: "submetidos à urgência, que jamais favoreceu à refle$x \tilde{a} o$, propõem muitas vezes, sobre os problemas mais candentes, descrições e análises apressadas, e amiúde, imprudentes" (grifos meus). Em que medida isso também se aplica (ou tende a se aplicar) aos produtos científicos na SC?

Parece-me oportuna esta indagação uma vez que a despeito do discurso com que se reveste a SC brasileira e dos compromissos históricos que a marcam como movimento, o modelo de avaliação cientifica adotado nesse campo também tem sido aquele em que a relevância social nem sempre conta ante o peso de outros parâmetros. Por conseguinte, não se valorizam devidamente produtos voltados para o sistema de saúde, aprofundando a dificuldade de apropriação das pesquisas pela sociedade, ainda que financiadas com recursos públicos.

Isso deve merecer uma rigorosa análise, antes de nos apressarmos a afirmar um crescimento exponencial da produção cientifica no campo, ou da 'ciência brasileira', enquanto alguns pesquisa- dores vem alertando para a falácia desse modelo comentando sua lógica interna, e sua nocividade levando ao desencantamento do trabalho cientifico e à impossibilidade de uma dedicação apaixonada $a^{35}$, desdobrando-se no sofrimento e adoecimento dos pesquisadores e dos alunos ${ }^{36,37}$, muitas vezes, em um contexto do quanto mais, melhor; não importa do que (ou a que preço).

Se por um lado, tal regime pode favorecer o crescimento quantitativo de publicações em alguns segmentos e mesmo elevar o fator de impacto - ainda que, por vezes, induzido por práticas questionáveis quanto à sua adequação e fidedignidade $^{38}$, o resultado tem sido barreiras à interdisciplinaridade e à cooperação, já que no sistema Qualis (base das avaliações de produtividade no Brasil) impera uma lei para cada campo disciplinar. Assim, mecanismos improdutivos transformam parcerias e pesquisadores promissores em improdutivos e desinteressantes para a acumulação de capital cientifico de tais programas, apoiando a competição e o individualismo.

Contudo, se na polaridade campo é esta a visão de mundo, nas palavras de ordem do movimento sanitário e no ideário do sistema defendido pela SC como movimento, justiça e equidade figuram como princípios; esse paradoxo é o que mais me preocupa e quanto a isso preciso sublinhar: a adesão à atual política de produtividade vem criando um abismo e uma contradição entre as esferas da SC como produção do conhecimento e como movimento, uma vez que na primeira esfera se operacionaliza precisamente o que contradiz a segunda, tendo como protagonistas atores do próprio campo, consoante às normas de conformação dos comitês.

Diante desse cenário, indagamos: quais têm sido os desfechos para a PQSC? A resposta nos leva a muitas direções, todas elas apontando expressivos desafios para esse enfoque, tal como evidenciam as questões que passamos a elencar como estímulos à nossa reflexão no campo.

No que tange ao número de publicações científicas indexadas em periódicos internacionais, há que assinalar que se tais veículos já se mostram, muitas vezes, indiferentes ao que é contextualizado no Brasil no âmbito dos estudos epidemiológicos, muito mais difícil, por exemplo, é neles inserir discussões acerca de aspectos qualitativos, ainda que decisivos para a consolidação do SUS brasileiro. A isso se soma a desqualificação dos poucos veículos que escoam PQ, já que os parâmetros classificatórios se subordinam à visão de mundo do enfoque hegemônico ${ }^{36,39}$, o que, evidentemente, não significa que as demais 
visões não tenham qualidade, como acaba sendo a crença construída no campo.

A intensificação do ritmo, como é sabido, também coloca a tradição qualitativa em franca desvantagem, aspecto que se vincula ao fato de a natureza desse enfoque não se adequar à divisão do trabalho observada em outros modelos. Assertiva corroborada, por exemplo, pela média de autorias por artigo, conforme já descrito na literatura ${ }^{40}$.

Tudo isso, claro, não é fato isolado no processo de produção: a suposta inferioridade produtiva - a um só tempo, causa e efeito do processo de avaliação dos produtos por 'pares' - se vincula ao tema das políticas de Ciência \& Tecnologia, notadamente ao financiamento e às agendas do setor que não poderemos aqui analisar em toda a sua extensão.

Por último, e o mais importante: todo esse processo para existir precisa ser protagonizado e quem o protagoniza? No caso da SC brasileira como campo nas agências de fomento, pelos bolsistas de produtividade e alguns outros atores cuja autoridade no campo - capital social, no dizer de Bourdieu - lhes é atribuída preponderantemente pela visão de produtividade já antes comentada, perpetuando-se um ciclo gerador de inequidades entre os três núcleos de saberes que compõem o campo. Dada a posição hegemônica da tradição quantitativa, isso constitui, muito provavelmente, um dos mais importantes desafios a serem enfrentados na materialidade do campo, para a consolidação do enfoque qualitativo na SC.

Para além do assinalado, a reversão depende da formação de quadros, em escala e grau de maturidade que possam impactar as agendas no campo científico: um monumental desafio para quem protagoniza o ensino deste enfoque na $\mathrm{SC}$, conforme passamos a expor.

\section{O desafio da formação de pesquisadores qualitativos na saúde coletiva: como expandir sem perder a qualidade?}

Ao iniciar este tópico, uma primeira constatação é a lacuna no que concerne a discussões de avanços e dificuldades enfrentadas no ensino desse enfoque e, mais precisamente, a inexistência quase absoluta de literatura voltada ao tema do ensino da PQ no âmbito da saúde (coletiva).

Corroborando o que acabamos de afirmar, cabe registrar a ausência deste capítulo nas obras de referência - compêndios ou handbboks - relativas à $\mathrm{PQ}$, mesmo em âmbitos externos à $\mathrm{SC}$. Uma busca nas obras clássicas e mais referi- das $^{11,14,15,21,23,41}$ nos revela que, a despeito de aspectos não relativos ao método em sentido estrito, encontrarem espaço nesses textos englobando: "como publicar", "como construir um projeto", "como avaliar a qualidade de produtos", dentre outros temas, nada se fala sobre "como ensinar PQ". Contudo, conforme já aludido, o tema merece investimentos e não pode ser excluído em uma discussão dirigida aos desafios atuais que se apresentam para o enfoque qualitativo.

Um primeiro aspecto a destacar é que o modelo formador conflui em vários aspectos (até porque se vinculam) para o que acabamos de discutir acerca do modo de produção do conhecimento, o que conduz a mais uma indagação: quais as chances de reversão da atual equação entre o ensino deste enfoque e dos demais, no espaço da SC?

De inicio, é preciso observar que os estudantes ingressos nos cursos da saúde coletiva provêm de distintas formações na saúde e em outros campos, nos quais, grosso modo, o ensino do enfoque qualitativo é ausente ou muito rudimentar. Para os docentes dedicados à formação nesse enfoque, isso implica em responder a uma série diversificada de demandas, muitas delas de caráter instrumental. Outro fator importante é a formação e a bagagem epistemológica não apenas de quem chega aos cursos, mas, o que é mais preocupante, dos próprios docentes, dado não contarmos no Brasil com formações estruturadas em PQSC como ocorre em outras tradições.

Imersos como estamos em uma cultura da quantidade, à qual desde cedo nos acostumamos em nossos processos de socialização primária $a^{42}$, conteúdos voltados à mensuração, bem como aqueles que fundam o modelo biomédico nos são transmitidos desde o ensino fundamental, garantindo, assim, as bases das pesquisas nas tradições quantitativa e experimental. Em contrapartida, quais conteúdos são valorizados ao longo dos ciclos pré-universitários como base para uma postura qualitativa tal como antes definida? E em nível de graduação, qual curso na saúde oferece esta base? A resposta me parece clara: quase nada se aporta no que concerne aos fundamentos do enfoque qualitativo em saúde (coletiva). Mais que isso, o modelo formador neutraliza até mesmo a subjetividade dos educandos e os avalia mediante números. E as pósgraduações, seja na SC seja em outros campos, não podem suprir essa lacuna monumental que abrange conteúdos, habilidades e valores que deveriam ser desenvolvidos desde cedo, muito antes do ingresso na formação superior. 
Assim, o sistema favorece a reprodução e expansão de um contingente expressivo de pesquisadores aptos a operacionalizar outras tradições, sendo um extraordinário desafio formar um doutor no enfoque qualitativo capaz de produzir efeitos no campo, ou seja, influenciar os mecanismos, agendas e processos específicos que operam na produção de conhecimento e nas definições relativas à pesquisa e sua difusão (ou seja, na distribuição do capital científico, econômico e social) no campo SC.

Ao examinarmos, há pouco, o processo de produção do conhecimento no regime atual marcado pela produtividade, alertamos para certos paradoxos na SC, e certas contradições geradas pelo ritmo veloz, como a desumanização das práticas sociais e a redução de relações entre pessoas a relações $\mathrm{Eu}-\mathrm{Isso}^{43}$; sobretudo quando as novas tecnologias confundem fluxo de informação com comunicação dialógica. Pensamos que, dentre outros desfechos, alguns deles já aqui analisados, essa intensificação da produtividade se faz à custa da dedicação ao ensino, já que grande parte deste trabalho é realizada pelos mesmos pesquisadores que sustentam a produtividade dos programas, submetidos a adoecedoras contradições resultantes do conflito entre a dedicação ao ensino e a acumulação de distintas modalidades de capital advindas da produtividade em pesquisa. Sobretudo em um sistema de avaliação para o qual ensinar não é ser produtivo. Diante do exposto: Será que os valores que compõem o ideário das reformas na saúde confluem para o modelo de ensino em SC ou vem se reproduzindo hegemonicamente também nesse campo o formato tradicional?

Enquanto as respostas a questões como esta, apontarem que o desafio da formação ainda persiste, conforme acredito ser o caso em tela, será difícil refundar o sistema e as práticas de saúde, haja vista buscarmos torná-los o que ainda não somos. No que concerne ao enfoque qualitativo, sem profissionais adequadamente formados, como fica o desafio não só de construir, mas, sobretudo, de transferir os achados da PQ para os sistemas de saúde, alicerçando dimensões centrais das reformas no setor?

\section{Para concluir: acerca da apropriação social dos resultados das pesquisas qualitativas em saúde coletiva}

$\mathrm{Na}$ etapa atual de consolidação da RSB, a qualificação da atenção básica entendida como estratégia central de reorganização do sistema se situa no centro dos debates. Humanização, equi- dade e integralidade, dentre outros conceitos-força que circulam no discurso da SC e da RSB implicam em incluir a qualidade a partir de uma acepção pluridimensional, qualitativa e participativa. Neste ponto, parece-nos extremamente oportuna a advertência feita por Morin ${ }^{24}$ no trecho que segue: [...] quanto mais os problemas se tornam multidimensionais, maior a incapacidade depensar sua multidimensionalidade; quanto mais a crise progride, mais progride a incapacidade de pensar a crise.

Com efeito, por diversas vezes, experienciamos dificuldades de operacionalizar modelos de pesquisa multidimensionais combinando dimensões qualitativas com estudos quantitativos, pelo fato de os modelos tradicionais - ainda que não deem conta da complexidade dos objetos, se mostrarem mais simples e 'objetivos', além de se coadunarem com o ritmo veloz e outros aspectos da cultura acadêmica a que já aludimos. Tal situação, consoante Morin ${ }^{24}$, obriga a "[...] reduzir o complexo ao simples, isto é, a separar o que está ligado [...] sua visão determinista, mecanicista, quantitativa, formalista ignora, oculta ou dilui tudo o que é subjetivo, afetivo, livre e criador" (grifo do autor).

Os excertos acima se aplicam ao desencontro entre o que dispomos de estoque de conhecimento na SC e o que vimos assistindo na construção de modelos adequados ao cenário atual ${ }^{44} \mathrm{na}$ inventividade necessária ao redirecionamento do discurso da reforma que não pode se repetir como um mantra por não se tratar de doutrina ${ }^{45}$ mas um texto aberto a recriações. Em que medida esse discurso que até pode ter dado conta dos desafios centrais quando da emergência da SC como movimento precisa se atualizar em consonância com os complexos processos que respondem pelos desfechos atuais? Desfechos estes repetidamente mensurados, mas ainda insuficientemente compreendidos na diversidade dos territórios e grupos que compõem um país, no caso, o Brasil.

Precisamos inocular o campo da Saúde Coletiva Humana, com o que é subjetivo, afetivo, livre e criador - e este é o aporte primordial do enfoque qualitativo cuja contribuição já abrange a quase totalidade dos objetos e temas da $\mathrm{SC}^{46,47}$. Mais que isto, para além dessas constatações atinentes à expressividade dos aportes da $\mathrm{PQ}$, nem sempre visualizados, precisamos pensar formas de impactar não apenas o campo científico, mas democratizar o conhecimento. Assim, cabe interrogar: $\mathrm{O}$ que vem sendo feito com os resultados das pesquisas qualitativas? Quais as eventuais barreiras e qual agenda para ultrapassar os obs- 
táculos? Tais questões nos reconduzem a vários elementos comentados em tópicos anteriores, reforçando a necessidade de uma visão sistêmica (complexa) na consideração dos desafios aqui discutidos cuja sinergia não pode ser esquecida.

A questão acerca do vem sendo feito com os resultados pede um posicionamento quanto à propriedade dos mesmos e seus usos, levandonos a um distanciamento tantos de visões utilitaristas como de posições indiferentes à sua utilização, como se a finalidade do saber produzido fosse tão somente repousar em volumes nas prateleiras das universidades ou nos curricula vitae dos pesquisadores. A questão da apropriação social não é meramente técnica; é ético-política.

$\mathrm{O}$ direito ao conhecimento integra a cidadania; o monopólio da ciência por parte dos experts e técnicos regride a competência democrática ${ }^{24}$, favorecendo, conforme se observa nos dias atuais, a expansão de comportamentos vinculados a interesses de segmentos que controlam meios poderosos de disseminação de discursos, notadamente a mídia. Circunscrevendo o tema à SC, já mencionamos aportes do enfoque qualitativo ao campo, o que nos dispensa de reiterá-los. Mas, o que deve ser transferido? Como? Por quem?

Percorrendo as questões acima, é evidente que devemos transferir todo o conhecimento que seja útil à elucidação e superação dos problemas sociossanitários. Na PQ impõe-se amplo acesso aos resultados e o direcionamento da investigação, aproximando academia, serviços, gestão e comunidade.

Da mesma forma e, talvez, de modo ainda mais refinado que para os demais enfoques, há que ter habilidades para entender, contextualizar e traduzir os resultados das pesquisas qualitativas que, envolvendo interpretações e distintos pontos de vista, contradições e mediações, não podem ser reduzidos a prescrições. Os problemas surgem quando esbarramos na escassez de pessoal capacitado tanto para a pesquisa como para sua aplicação (quem), bem como na adequação e alcance dos veículos (como).

Quando da análise do processo de produção do conhecimento, discutimos a necessária articulação com todas as formas de linguagem, para as quais as pesquisas podem aportar conteúdo. Entretanto, podemos afirmar que ainda estamos engatinhando no âmbito da difusão de resultados na saúde; também aqui, o produtivismo restringe sobremaneira as possibilidades de recriar formas de divulgação.

Ainda assim, suspeito que oportunidades que vem surpreendendo em linhas mais abertas ao livre pensar, solidamente alicerçadas na produção de renomados pesquisadores no domínio da PQ, podem fazer emergir novos protagonismos na academia, nos serviços, nos vários grupos e comunidades que protagonizam o campo SC. Se é certo que o momento atual nos confronta inexoravelmente e cada vez com mais força com os desafios da complexidade, então talvez nessa crise se encontre a oportunidade de: tecer esperanças em uma (re)valoração da ciência e da pesquisa; sonhar com novas alianças entre enfoques e saberes; e com o resgate da alegria e do encantamento com o fazer científico apaixonado, longe das amarras de uma produtividade muitas vezes estéril, adoecedora e alienante. Um projeto que nos conduza a um novo tempo no qual os desafios aqui assinalados não sejam mais contemporâneos. 


\section{Referências}

1. Uchimura KY, Bosi MLM. Qualidade e Subjetividade na Avaliação de Programas e Serviços de Saúde. Cad Saude Publica 2002; 18(6):1561-1569.

2. Bosi MLM, Uchimura KY. Avaliação da Qualidade ou Avaliação Qualitativa da Atenção? Elementos para uma demarcação conceitual. Rev Saude Publica 2007; 41(1):150-153.

3. Bourdieu P. O campo científico. In: Ortiz R, organizador. Pierre Bourdieu. São Paulo: Ática; 2003.

4. Khun T. A estrutura das revoluções científicas. São Paulo: Perspectiva; 1978.

5. Bosi MLM, Prado SD. O Campo da Alimentação e Nutrição em Saúde Coletiva: constituição, contornos e estatuto científico. Cien Saude Colet 2011; 16(1):7-17.

6. Paim JS. Desafios para a saúde coletiva no século XXI. Salvador: EDUFBA; 2006.

7. Lima NT, Santana JP. Saúde Coletiva como compromisso. A trajetória da ABRASCO. Rio de Janeiro: ABRASCO, Ed. Fiocruz; 2006.

8. Nunes ED. Saúde coletiva: uma história recente de um passado remoto. In: Campos GWS, Minayo MCS, Akerman M, Drumond Júnior M, Carvalho YM. Tratado de Saúde Coletiva. São Paulo, Rio de Janeiro: Hucitec, Ed. Fiocruz; 2009. p. 295-315.

9. Amezcua M, Garricondo A. Investigación Cualitativa en España. Análisis de la producción bibliográfica en salud. In: Mercado FJ, Gastaldo D, Calderon C. Paradigmas y diseños de la Investigación Cualitativa en salud. Una antología Iberoamericana. Guadalajara: Universidad de Guadalajara, Universidad Autónoma de Nuevo León; 2002. p. 120-132.

10. Gruppi L. O conceito de hegemonia em Gramsci. 2a ed. Rio de Janeiro: Graal; 1980.

11. Tesch R. Qualitative Research. Analysis types \& software tools. New York: The Falmer Press; 1995.

12. Mercado FJ, Lizardi A, Villasenor M. Investigación Cualitativa en Salud en América Latina. Una aproximación. In: Mercado FJ, Gastaldo D, Calderón C. Paradigmas y Diseños de La Investigación Cualitativa en Salud. Guadalajara: Ed. Universidade de Guadalajara; 2002.p.133-1580.

13. Martínez FJM, Bosi MLM. Pesquisa Qualitativa: Notas para um Debate. In: Bosi MLM, Mercado FJ, organizadores. Pesquisa Qualitativa de Serviços de Saúde. 2a ed. Petrópolis: Editora Vozes; 2004. p. 23-72.

14. Denzin NK, Lincoln YS. Handbook of Qualitative Research. $2^{\text {nd }}$ ed. California: Sage; 2000.

15. Creswell JW. Research Design: Qualitative \& Quantitative Approaches. London: Sage; 1994.

16. Conde F. Encuentros y desencuentros entre la perspectiva cualitativa y la cuantitativa en la historia de la medicina. Revista Esp Salud Publica 2002; 76(5):395-408.

17. Denman CA, Haro J A. Trayetoria y Desvarios de los Métodos Cualitativos en la Investigación Social. In: Mercado FJ, Gastaldo D, Calderón C. Paradigmas y Diseños de La Investigación Cualitativa em Salud. Guadalajara: Ed. Universidade de Guadalajara; 2002. p. 35-72.

18. Abusabha R, Woelfel ML. Qualitative vs quantitative methods: two opposites that make a perfect match. J Am Diet Assoc 2003; 103(5):566-569.
19. Flick U. Pesquisa qualitativa e quantitativa. In: Flick U. Introdução à pesquisa Qualitativa. Porto Alegre: Artmed-Bookman; 2009. p. 39-49.

20. Gênesis (11:1-9). In: Bíblia Sagrada. Nova tradução na linguagem de hoje. São Paulo: Paulinas Editora; 2005. p.11.

21. Creswell JW. Qualitative Inquiry \& Research Design: Choosing among five traditions. London: Sage; 2007.

22. Morse J, Field A. Qualitative Methods for Health Professionals. Thousand Oaks: Sage; 1995.

23. Patton MQ. Qualitative Research \& Evaluation Methods. London: Sage; 2002.

24. Morin E. A cabeça bem feita. 9a ed. Rio de Janeiro: Bertrand do Brasil; 2004.

25. Santos BS, Meneses AP, organizadores. Epistemologias do Sul. São Paulo: Cortez; 2010.

26. Morin E. A religação dos saberes. O Desafio do século XXI. $3^{\text {a }}$ ed. Rio de Janeiro: Bertrand do Brasil; 2002.

27. Denzin NK. Apocalypse Now: overcoming resistances to qualitative inquiry. International Review of Qualitative Research 2009; 2(2):331-343.

28. Green J, Thorogood N. Qualitative research for health methods. Thousand Oaks: Sage; 2009.

29. Russell G, Kelly N. Research as Interacting Dialogic Processes: Implications for Reflexivity. Forum Qualitative Sozialforschung/Forum: Qualitative Social Research, North America, 3, sep, 2002. [cited 2012 Jan 27] Available from: http://www.qualitativeresearch.net/index.php/fqs/article/view/831.

30. Mruck K, Breuer F. Subjectivity and Reflexivity in Qualitative Research-The FQS Issues. Forum Qualitative Sozialforschung/Forum: Qualitative Social Research, North America, 4, may, 2003. [cited 2012 Jan 27] Available from: http://www.qualitativeresearch.net/index.php/fqs/article/view/696/1504

31. Tilley SA. "Challenging" Research Practices: Turning a critical lens on the work of transcription. Qualitative Inquiry 2003; 9(5):750-773.

32. Gibbs G. Analysing Qualitative Data. Thousand Oaks: Sage; 2007

33. Guillemin M, Gillam L. Ethics, reflexivity, and "ethically important moments" in research. Qualitative Inquiry 2004; 10(2):261-280

34. Bourdieu P. Compreender. In: Bourdieu P. A Miséria do Mundo. Petrópolis: Vozes; 1997. p. 733.

35. Weber M. A Ciência como vocação. In: Weber M. Ensaios de Sociologia. Rio de Janeiro: Ed Guanabara; 1982.

36. Luz MT. Prometeu acorrentado: análise sociológica da categoria produtividade e as condições atuais da vida acadêmica. Physis 2005; 15(1):39-57.

37. Rocha-e-Silva M. O Novo Qualis, que não tem nada a ver com a ciência do Brasil: carta aberta ao presidente da CAPES. Clinics 2009; 64(8):721-724.

38. Metze K. Bureaucrats, researchers, editors, and the impact factor - a vicious circle that is detrimental to science. Clinics 2010; 65(10):937-940.

39. Gastaldo D, Bosi MLM. ¿Qué significa tener impacto? Los efectos de las políticas de productividad científica en el área de salud [Editorial]. Enfermería Clínica 2010; 20(3):145-146. 
40. Camargo Júnior KR, Coeli CM, Caetano R, Maia VR. Produção intelectual em saúde coletiva: epistemologia e evidencias em diferentes tradições. Rev Saude Publica 2010; 44(3):394-398.

41. Silverman D, Marvasti A. Doing Qualitative Research: A comprehensive guide. Thousand Oaks: Sage; 2008.

42. Berger P, Luckmann T. A construção social da realidade. 33a ed. Petrópolis: Vozes; 2011.

43. Buber M. Do diálogo e do dialógico. São Paulo: Perspectiva; 2009.

44. Flick U, Salomon A. Mixing Methods, Triangulation and Integrated Research: Challenges for Qualitative Research in a World of Crisis. In: Denzin N, Giardina MD. Qualitative Inquiry and Global Crisis. Thousand Oaks: Sage; 2011.

45. Morin E. Ciência com consciência. 14a ed. Rio de Janeiro: Bertrand do Brasil; 2010.

46. Martínez FJM, Gastaldo D, Bosi MLM, Carvalho S, Wiessenfeld E, Sánchéz E, Fuentes-Uribe IX. Health Policy and Programs Evaluative Research for Social Change. Forum Qualitative Sozialforschung 2008; 9(2):19-26.

47. Bosi MLM, Martínez FJM. Modelos avaliativos e reforma sanitária brasileira: acerca do enfoque qualitativo-participativo. Rev Saude Publica 2010; 44(3): 566-570. 